\title{
MÉXICO Y LA SOCIEDAD DE NACIONES: SOBRE SU EXCLUSIÓN E INGRESO (1919-1931)
}

\author{
Fabián Herrera León \\ Universidad Michoacana de San Nicolás de Hidalgo
}

ANTECEDENTES, AMBIGÜEDADES Y MALENTENDIDOS

\begin{abstract}
unque conserva su singular y público atractivo, la trayectoAria de México por la Ginebra internacional de entreguerras ha merecido una atención eventual y selectiva de parte de los estudiosos, no obstante su evocación recurrente -y habitualmente desmesurada- de los episodios de política internacional más conocidos: ingreso tardío a la Sociedad de Naciones, Manchuria, Etiopía, España, Austria y Checoslovaquia (crisis de los Sudetes). ${ }^{1}$ Bien espaciados por décadas, algunos cuantos han
\end{abstract}

Fecha de recepción: 22 de abril de 2019

Fecha de aceptación: 10 de septiembre de 2019

${ }^{1}$ Pongo como ejemplo a Martínez Legorreta, Actuación de México en la Liga, p. 99; OJeda Revah, "El frente diplomático", p. 768; Serrano Migallón, Isidro Fabela, pp. 37-54; MÁrquez MuÑoz, "La política exterior del cardenismo”, pp. 370-379, 392-394, 407-410; OJeda Revah, México y la Guerra Civil española, pp. 110-111; López-BAssols, "México en la encrucijada”, p. 82; Aguilar Monteverde, Narciso Bassols; Cárdenas, Cárdenas por Cárdenas, pp. 407-440; De la Pedraja y Muñoz, "La admisión de los Estados de América Latina”, p. 395; FABELA, Cartas al presidente. La política 
ofrecido testimonios o apreciaciones históricas sobre la no invitación a México a la nueva organización internacional fraguada en Versalles y, finalmente, sobre su incorporación a la misma años después. Lo primero, escrito la mayoría de las veces en términos de condena e indignación, recalcando el desinterés expresado por el gobierno de Venustiano Carranza (1917-1920) por una organización que validaba la doctrina Monroe en su Pacto constitutivo (artículo 21); ${ }^{2}$ y lo segundo, prácticamente sin excepciones, con una voz triunfal y redimida, describiendo cómo las principales potencias societarias de la época -presentes en la Asamblea General de 1931- ofrecieron una disculpa pública a

del presidente; GuIllén, Fabela y su tiempo; OJEda RevaH, "La dimensión internacional”, pp. 33-42; SÁINZ, "México frente a la anexión”, pp. 67-68; Ortuño Martínez, “Cárdenas, México y España”.

2 Artículo 21: "Los convenios internacionales, como por ejemplo los Tratados de arbitraje, y las Convenciones sobre determinados territorios, como la doctrina Monroe, que aseguran el mantenimiento de la paz, no se considerarán incompatibles con ninguna de las disposiciones del presente Tratado”. El Pacto de la Sociedad de Naciones, tal como fue enviado a Venustiano Carranza desde París por Alberto J. Pani, su observador en la Conferencia de Paz, se halla entre los documentos de un compendio que presenté recientemente: Herrera León, México y la Sociedad de Naciones. Una antología documental, pp. 61-72. La interpretación de Carranza era ciertamente la más lógica, coincidente incluso con el entender de las potencias europeas respecto de los intereses continentales estadounidenses, en la que se apreciaba como una natural e inmediata esfera de influencia. Otra interpretación contemporánea advertía una multilateralización de la doctrina Monroe, pero esta se alejaba no solamente del motivo de su inserción en el Pacto, que había sido facilitar la ratificación estadounidense del Tratado de Versalles para asegurar la participación de esta potencia en la Sociedad de Naciones, sino también de su perfil ambiguo y restrictivo, capaz de desanimar el involucramiento de Ginebra en diferendos latinoamericanos durante poco más de una década, hasta que fue interpretada por la sección jurídica de la organización y de su propio Consejo en forma no excluyente ni limitante y esto fue confirmado en la práctica con su involucramiento en los conflictos del Chaco y Leticia. Sobre la cuestión general de la mención de la doctrina Monroe en el Pacto, que siempre fue más de orden político que jurídico, sugiero la consulta de WEHRLI, "Etats latinoaméricains”, pp. 355-406. 
México y solicitaron su inmediata incorporación a la Sociedad de Naciones "como si hubiera sido invitado desde el origen", dejándole -supuestamente- hacerlo con reservas formales al Pacto. ${ }^{3}$ Con cierta recurrencia, los especialistas en el estudio de las relaciones hispanomexicanas suelen exagerar igualmente el episodio, subrayando cómo los buenos oficios (cabildeo internacional) de la Segunda República española no facilitaron sino que condujeron de forma exclusiva y segura a su par internacional a Ginebra, ${ }^{4}$ algo que parecería confirmarlo la comida que España y el resto de naciones latinoamericanas ofrecerían a la delegación mexicana al día siguiente de su recibimiento formal. ${ }^{5}$ Así que, entre este tipo de versiones e interpretaciones breves y selectivas, ha cabido poca modestia al tener como propósito la exaltación de personajes políticos y diplomáticos, lo mismo que de sus decisiones: la primera, la del gobierno de Pascual Ortiz Rubio (1930-1932) de concluir con esta etapa poco prometedora de retraimiento y, posteriormente las correspondientes a las causas internacionales durante el periodo de gobierno de Lázaro Cárdenas (1934-1940). De allí, pues, la insistencia en el

${ }^{3}$ Legendariamente, desconociendo el artículo 21 del Pacto, como entre otros se lee en Zea Prado, "México en la Sociedad de Naciones", pp. 117-118; Seara Vázquez, Tratado general, pp. 59-60; Díaz, Historia de las relaciones internacionales, p. 39; OJEDA REVAH, "El frente diplomático", p. 770; OJEDA Revah, “En busca de un lugar”, p. 205.

${ }^{4}$ Sirvan de ejemplo trabajos sumamente atinados y reconocidos en el ámbito de su verdadera especialidad: Matesanz, Las raíces del exilio, pp. 191-192; Ojeda Revah, "El frente diplomático", p. 769; Ojeda Revah, México y la Guerra Civil española, p. 70; MeYer, "Alberto J. Pani”, pp. 97-98; García GutiérRez, "La pluma y la acción”, p. 107; Pi-SuÑER, Riguzzi y Ruano, Europa, p. 299; SÁnchez ANDrés, "El espejo invertido", p. 41; SÁNCHEz ANDrÉs y Pérez Herrero, Historia de las relaciones entre España y México, p. 145. Aciertan al reconocer una contribución parcial de la diplomacia española a este fin Díaz y Martini, Relaciones diplomáticas México-España, p. 260; Tirado SÁnchez, "La política exterior del México cardenista", pp. 23, 69.

5 Portes Gil, Autobiografía de la revolución, pp. 668-669; Portes Gil, Historia vívida, pp. 631-632. 
referido mea culpa frente a México de las potencias de Ginebra en el curso de la Asamblea de 1931 para determinar su ingreso, ${ }^{6}$ una ocasión ciertamente única -e igualmente anecdótica- en la historia de la Sociedad de Naciones.

En adelante, como ya hemos mencionado, la versión historiográfica dominante hace un recorrido breve, con atención exclusiva en lo político, que corresponde a la representación de Isidro Fabela en la Sociedad de Naciones y cuyas estaciones se llaman Manchuria (sin relación con el origen de la invasión japonesa en 1931), Etiopía (en realidad, el desenlace del conflicto), ${ }^{7}$ España, Austria y Checoslovaquia. Tales son los casos centrales de Cartas al presidente Cárdenas de Isidro Fabela, ${ }^{8}$ obra y fuente hegemónica de esa corriente exaltada en torno a justas y caballeros de la diplomacia mexicana, nada más y nada menos que el capítulo ejemplar y emblemático de una idea -con visos de escuela- de política exterior tradicional y acertada. ${ }^{9} \mathrm{El}$ final o consumación es precisamente este, y episodios posteriores y

${ }^{6}$ La documentación que conservó la sección mexicana de la Sociedad de $\mathrm{Na}$ ciones acerca del ingreso de México en esa organización fue publicada a finales de la década de 1970, pero no consiguió desambiguar la cuestión ni evitar la repetición de atractivas y románticas explicaciones. Véase Díaz y MarTini, Relaciones diplomaticas México-España, pp. 256-280.

7 Esto es el "no debate" sobre la aplicación de sanciones de peso contra Italia, sin pronunciamientos claros al respecto de parte de la diplomacia mexicana, seguido del levantamiento sin complicaciones -no objetado tampoco por México- de las primeras sanciones económico-financieras, hasta el episodio de desenlace, realmente exagerado por Fabela, en el que la delegación mexicana a su cargo se opone a la eliminación del nombre de Etiopía -entonces invariablemente vencida y anexada al nuevo imperio italiano- de la lista de países miembros (documentación oficial) de la Sociedad de Naciones. Véase Herrera León, "Mexico and its 'Defense' of Ethiopia”.

${ }^{8}$ Cuenta con una adaptación como libro en La política internacional de Cárdenas.

9 He reflexionado al respecto en "El paso de México por la Socieadad de Naciones: la construcción retórica de una trayectoria y destino". 
presentes de la vida internacional de México habrán de ser medidos con ese gigante.

Pero este artículo está pensado solo para el comienzo de esta historia, ${ }^{10}$ del que se ha hecho también un episodio legendario que inicia desventajosamente con la decisión de exclusión, sobre la que considero debe reflexionarse seriamente por su carácter relevante de "primer capítulo" de una historia que seguiría una trayectoria irregular en comparación con la de la mayoría de miembros de esta organización. ${ }^{11}$ Me refiero, pues, a un mal comienzo que como tal exige un cuestionamiento y revisión que nos permita apreciar las principales motivaciones de una variedad de actores internacionales, el propio Carranza entre ellos, que determinaron una medida de marginación únicamente comparable a la decidida para las potencias derrotadas en la primera guerra mundial, quizá porque la revolución mexicana dio reiteradas muestras de una beligerancia en la sombra a favor de Alemania y sostuvo su amenaza a las inversiones extranjeras, principalmente en el sector petrolero, mediante las modificaciones constitucionales de 1917 y la sustracción del subsuelo del régimen de propiedad privada. Asimismo, creo pertinente y necesaria una interpretación menos desfavorecedora de este episodio de separación de la revolución mexicana del nuevo sistema internacional, donde la distancia de Ginebra podría tener cierto simbolismo y utilidad, si consideramos el retraimiento

${ }^{10}$ La etapa posterior de colaboración de México con Ginebra ha sido objeto de una actualización y revisión historiográfica en los últimos 15 años, de forma general como acotada a distintos episodios de crisis internacional y a otros ámbitos de colaboración de carácter técnico e intelectual. He realizado apreciaciones de estos trabajos en el estudio introductorio "México y la Ginebra internacional de entreguerras, 1919-1939" a México y la Sociedad de Naciones. Una antología documental, pp. 15-32 y en "El paso de México por la Sociedad de Naciones la construcción retórica de una trayectoria y destino", pp. 333-335.

${ }^{11}$ La historia clásica de la Sociedad de Naciones podría ser muy ilustrativa al respecto. Walters, Historia de la Sociedad de Naciones. 
una ocasión útil para la planeación y reconfiguración de una política exterior prudente para salir de su aislamiento y distintiva al conseguirlo del todo, tal como me atrevo a sugerir ocurrió con la cancillería mexicana bajo la influencia de Genaro Estrada.

El agravio con motivo de la exclusión, es cierto, fue sorpresivo para la opinión pública y sociedad mexicanas pese a la tirante relación entre la revolución mexicana y las potencias que se dieron cita en París para finiquitar la derrota alemana y moldear la paz, y un renovado sistema internacional. ${ }^{12}$ Pero esto no fue así para el gobierno de Venustiano Carranza, que no contaba con el reconocimiento de las principales potencias aliadas ${ }^{13}$ y que se hallaba envuelto, decidida y persistentemente, en una empresa conspirativa contra Estados Unidos, la cual, interpretada como una defensa de la soberanía, no concluiría sino con la muerte del primer jefe constitucionalista. Asimismo, el curso violento e incesante de la revolución mexicana representaría un peso importante más, atribuible tanto a los cambios abruptos de gobierno por la lucha de facciones, como a la afectación efectiva o velada sobre personas, bienes e inversiones extranjeros, en particular de potencias aliadas como Estados Unidos, Gran Bretaña y Canadá. ${ }^{14}$ Sus representantes, como Edward L. Doheny, se harían cargo personalmente del asunto y no escatimarían tiempo ni esfuerzo en su labor de convencimiento en el escenario parisino de la Conferencia de Paz. La rebeldía revolucionaria mexicana y sus formas ofensivas, ${ }^{15}$ tanto en la política internacional

12 Creo pertinente la lectura de una profunda reflexión contemporánea a este respecto. CARR, La crisis de los veinte años. También la de una historia inigualable de esos importantes y determinantes días en la capital francesa. MacMillan, París, 1919.

13 WeHrLI, “États latino-américains”, p. 138.

${ }^{14}$ Un contexto muy bien acotado en Pi-Suñer, Riguzzi y Ruano, Europa, pp. 251-260.

${ }^{15}$ En sus reportes y memoranda regular secreta para uso exclusivo del Foreign Office y el War Cabinet británicos se registrarían consistentemente la arrogancia y altivez del presidente Carranza, así como su inclinación y 
carrancista (esbozada desde 1915 y condensada en 1918) ${ }^{16}$ como en la nueva Constitución de 1917, tampoco tenían nada de agradables ni tranquilizadoras, como este gobierno suponía podría serlo, para las potencias agraviadas en bienes e intereses, la expedición del reglamento de reclamaciones de diciembre

toleración a las operaciones alemanas de espionaje. Es el caso de los siguientes documentos de Gabinete: Western and General Report, Part II Foreign and General, núm. 54, Londres, 6 de febrero de 1918, ANRU, CAB, 24/148, imag. ref. 0005; Western and General Report, núm. 122, Londres, 4 de junio de 1918, ANRU, CAB/24/150, imag. ref. 0028; Western and General Report, núm. 72, Londres, 12 de junio de 1918, ANRU, CAB/24/148, imag. ref. 0023; Western and General Report, núm. 82, Londres, 21 de agosto de 1918, ANRU, CAB/24/149, imag. ref. 0007; Western and General Report, núm. 84, Londres, 4 de septiembre de 1918, ANRU, CAB/24/149, imag. ref. 0009; Western and General Report, núm. 88, Londres, 2 de octubre de 1918, ANRU, CAB/24/149, imag. ref. 0013; Western and General Report, núm. 95, Londres, 20 de noviembre de 1918, ANRU, CAB/24/150; imag. ref. 0001; Western and General Report, núm. 100, Londres, 1 de enero de 1919, ANRU, CAB/24/150, imag. ref. 0006; Western and General Report, núm. 104, Londres, 29 de enero de 1919, ANRU, CAB/24/150; imag. ref. 0010; Western and General Report, núm. 108, Londres, 26 de febrero de 1919, ANRU, CAB/24/150, imag. ref. 0014; Western and General Report, núm. 112, Londres, 26 de marzo de 1919, ANRU, CAB/24/150, imag. ref. 0018; Western and General Report, núm. 125, Londres, 25 de junio de 1919, ANRU, $\mathrm{CAB} / 24 / 150$, imag. ref. 0031; Western and General Report, núm. 127, Londres, 9 de julio de 1919, ANRU, CAB/24/150, imag. ref. 0033; Western and General Report, núm. 130, Londres, 30 de julio de 1919, ANRU, CAB/24/150, imag. ref. 0036; Western and General Report, núm. 133, Londres, 20 de agosto de 1919, ANRU, CAB/24/150, imag. ref. 0039; Foreign Countries Report, núm. 4, Londres, 19 de noviembre de 1919, ANRU, CAB/24/154, imag. ref. 0004.

${ }^{16}$ La llamada "doctrina Carranza", inspirada en la tradición política americana de naturaleza autodefensiva, evoca, en este primer momento, el espíritu deseable de la política exterior mexicana y sus opuestos: la tutela innecesaria y antisoberana estadounidense representada por la doctrina Monroe; la igualdad de todas las naciones frente al derecho internacional, así como el respeto del exterior a leyes e instituciones propias; la igualdad ante la ley de nacionales y extranjeros; y la sana equidistancia de los Estados nacionales y su diplomacia frente a los intereses y negocios de sus connacionales en el extranjero. El eco nítido de las doctrinas Calvo (1868, por la igualdad ante la ley nacional de los 
de 1917. ${ }^{17}$ Finalmente, para molestia e inquietud de muchos más, sobrevivía en México una revolución que se decantaba así como nacionalista y que era por motu proprio peligrosamente contagiosa en una región latinoamericana que observaba los mismos problemas e impedimentos a su libre curso y que esa revolución parecía resolver; así miraban las cosas los potenciales revolucionarios que amenazaban la permanencia en el poder de un abanico multiforme de autocracias latinoamericanas oxigenadas materialmente por las mismas potencias mundiales. ${ }^{18} \mathrm{En}$ esta circunstancia, Alberto J. Pani, a cargo de la representación mexicana en París, ${ }^{19}$ asistiría como observador oficioso a las sesiones públicas de la Conferencia de Paz e informaría detalladamente de su curso al propio Carranza, en especial del proyecto de Sociedad de Naciones y de su Pacto constitutivo. ${ }^{20}$

extranjeros) y Drago (1902, contra el uso de la fuerza en el cobro de deudas entre naciones) nos remite al problema común y reiterado de insuficiencia y debilidad interior de las jóvenes repúblicas americanas. Sobre las doctrinas Calvo y Drago y su presencia en el ambiente político latinoamericano, véase Carrillo Reveles, "México en la Unión de las Repúblicas”, pp. 31, 47-49, 62. Y brevemente sobre la doctrina Carranza y su condensación, MeYer, La marca del nacionalismo, pp. 33-35.

17 Portes Gil, Autobiografía de la revolución, p. 344.

18 Sobre la diseminación de propaganda revolucionaria mexicana en Sudamérica por medio de sus representaciones diplomáticas recomiendo ampliamente el libro de Palacios, América del Sur, en específico los capítulos "Reconstrucción" y "Los años rojos".

19 Este, a diferencia de Rafael Nieto y de Juan Sánchez Azcona, sí pudo contar con el beneplácito del gobierno francés para encabezar la legación en razón de su conocida simpatía por las potencias aliadas y asociadas. Sin embargo, la diplomacia francesa tuvo muy presente el favoritismo del gobierno de Carranza por los imperios centrales y actuó fría y desairadamente en todo este proceso de normalización de relaciones que tomó cuatro meses. PANi, Alberto G. Pani. Ensayo biográfico, pp. 123-126.

20 Véase PAni, Cuestiones diversas en 44 cartas, pp. 23-24, 218-228, 261-267. 


\section{LA PRIMERA POSGUERRA Y LA REVOLUCIÓN MEXICANA:}

\section{LA EXCLUSIÓN}

Tras bambalinas, las potencias de París hablarían privadamente de México y del llamado "embrollo mexicano", ${ }^{21}$ eufemismo anglófono, del que no dejaba de hacer eco Francia, ${ }^{22}$ para hablar de una revolución que se hacía necesario controlar y limitar a su espacio de desarrollo, algo equivalente a aislarla para poder ocuparse de ella. ${ }^{23}$ ¿De qué forma? La propuesta más extrema sobre la mesa sería la de la diplomacia británica y consistía en desmantelarla hasta su estructura estatal y colocarla en calidad de dominio bajo su tutela, ${ }^{24}$ aprovechando el nuevo sistema

${ }^{21}$ MacMillan, París, 1919, p. 37; Lazo, “Lansing, Wilson, and the Jenkins”, p. 183.

22 PAni, Alberto G. Pani. Ensayo biográfico, p. 125; Portes GIL, Autobiografía de la revolución, pp. 343-344.

${ }_{23}$ Antonia Pi-Suñer, Paolo Riguzzi y Lorena Ruano tienen una noción clara sobre este particular problema con las potencias aliadas: "El riesgo de que la neutralidad carrancista encubriera una colaboración militar con Berlín, junto con la política mexicana en relación con el petróleo, cristalizada en las disposiciones que otorgaban retroactividad a las normas constitucionales, fueron la fuente principal de tensión entre México y los aliados. Los tonos proalemanes de posición mexicana en la contienda mundial fueron percibidos de manera recurrente por parte de británicos, franceses y estadounidenses, y en determinados momentos hicieron pensar que la cuestión petrolera en México tenía que interpretarse en función de la postura progermánica de Carranza y de la intención de perjudicar a los aliados". Pi-SuÑER, RiguzZI y Ruano, Europa, p. 253. ${ }^{24}$ Previamente se había hablado de la posibilidad, en atención a la doctrina Monroe y su validación internacional mediante el Pacto de la Sociedad de $\mathrm{Na}-$ ciones, de que Estados Unidos asumiera la responsabilidad de tutor. Desde la embajada británica en Estados Unidos, Colville Barclay lo ponía en términos muy claros: "Desde que la doctrina Monroe ha sido específicamente reconocida en el borrador del plan para la Liga de las Naciones se considera seguro, por si existía alguna duda, que Estados Unidos debe convertirse inevitablemente en la potencia mandataria de Mexico". Colville Barclay al secretario de Estado para los Asuntos Exteriores, Washington, 16 de abril de 1919, ANRU, FO, 539/2/2, "Situation in Mexico". 
de mandatos que coordinaría la Sociedad de Naciones. ${ }^{25}$ Esto era algo más, incluso, que la intervención binacional sugerida todavía a principios de 1919, como un eco de la "espera vigilante" de Wilson, ${ }^{26}$ por el representante estadounidense en México al británico, apenas encargado del archivo, pero escuchado por el Foreign Office como si se tratara de un ministro. ${ }^{27}$ Aunque

${ }^{25}$ David Hunter Miller, asesor jurídico estadounidense de la Conferencia y uno de los principales proyectistas del Pacto, conservaría una copia de la propuesta británica. Véase Miller, My Diary at the Conference, p. 442. Curiosamente, esta misma idea se aprecia destacada en color rojo en un extenso memorándum acerca de la situación interna y externa de México filtrado a la diplomacia británica por un miembro del servicio militar de inteligencia estadounidense. En su punto XI, titulado "Muchos mexicanos desean la intervención", puede leerse: "Entre las clases mejor educadas, aquellas que desean la intervención, expresan la esperanza de que esta tenga lugar a través de la Conferencia de París o como un mandato de la Sociedad de Naciones. Sienten que México no resentiría una humillación grave en el caso de una intervención de varias naciones europeas trabajando de cerca con Estados Unidos o solo por los Estados Unidos haciendo cumplir un mandato de la Sociedad de las Naciones. Pero ante el fracaso colectivo de las naciones extranjeras con intereses en México, ellos preferirían la intervención de Estados Unidos que la continuación del actual régimen de corrupción y opresión." Colville Barclay al secretario de Estado para los Asuntos Exteriores, Washington, 10 de marzo de 1919, ANRU, FO, 539/2/1, "Situation in Mexico". La prensa estadounidense difundiría la idea de una tutela británica, la cual encontraría eco en la opinión pública mexicana. Véase ANRU, FO, 539/2/2, "Report that Great Britain will be Mandatory for Mexico under League of Nations", "Rumoured British Mandate for Mexico" y "British Intervention in Mexico".

26 Véase al respecto Herrera y Santa Cruz, América del Norte, pp. 194-199.

27 La propuesta del estadounidense era informada por la diplomacia inglesa de manera secreta y confidencial en los siguientes términos: "Durante la conversación de hoy con el embajador de los Estados Unidos, coincidimos en que la situación aquí es quizás peor que nunca [...] Discutimos los atrevidos abusos de Carranza en relación con los intereses extranjeros, y el embajador se preguntaba cuánto más soportarían Inglaterra y Francia [...] Declaró, de hecho, que la administración Carranza debe su existencia a los ingresos que roba a las empresas extranjeras. Estos son principalmente británicos. El embajador se pregunta por qué el gobierno de su majestad no le sugirió al presidente Wilson una doble ocupación de México [...]”. Cunard Cummins al secretario 
inviable, el tema quedaba allí junto con el resto de problemas especiales que eventualmente habrían de resolverse en el curso de estas sesiones privadas y cuyo desenlace habría sido de enorme interés para el nutrido grupo de cabilderos internacionales que también se hallaban entonces en París, entre ellos Edward L. Doheny, de la estadounidense Huasteca Petroleum Company y cabeza de la National Association for the Protection of American Rights in Mexico, punta de lanza de la poderoso industria petrolera cuyos derechos de propiedad habían sido directamente amenazados por el precepto patrimonial que por la Constitución de 1917 consideraba el subsuelo propiedad de la nación; su intención era presionar ante las principales potencias de Versalles para impedir, cuando menos, el reconocimiento del gobierno de Carranza que podía darse implícitamente en una invitación como nación neutral a suscribir el Tratado de Paz e ingresar a la Sociedad de Naciones. ${ }^{28}$ Asimismo, la diplomacia británica obtendría información reservada del servicio militar de inteligencia estadounidense relacionada con Pani y el seguimiento de que era objeto, así como del supuesto cabildeo que en París llevaba a cabo por Francisco León de la Barra en representación de los "reaccionarios". Esta documentación filtrada registraba igualmente la esperanza de un sector de la sociedad mexicana en el eventual reconocimiento internacional al movimiento revolucionario dirigido por Félix Díaz. ${ }^{29}$ También

de Estado para los Asuntos Exteriores, México, 20 de enero de 1919, ANRU, FO, 608/174/12, "Situation in Mexico". Lorenzo Meyer es autor de la obra más importante sobre las complicaciones representadas por la política angloestadounidense para la revolución mexicana, aún más detallada respecto a esta diplomacia de tenaza y de absorción de México en la esfera de influencia estadounidense. Véase MeYer, Su Majestad británica, pp. 128-168.

${ }^{28}$ Véase Trow, "Woodrou Wilson and the Mexican Interventionist Movement”, p. 47 y para abundar en la problemática, la obra clásica de MeYer, México y los Estados Unidos.

${ }^{29}$ Colville Barclay al secretario de Estado para los Asuntos Exteriores, Washington, 10 de marzo de 1919, ANRU, FO, 539/2/1, "Situation in Mexico". 
el primer ministro canadiense, Robert Borden, abogaría ante el gobierno británico por una intervención en México antes de que las potencias quedaran atadas de manos con la puesta en marcha de la Sociedad de Naciones en razón del estado de anarquía existente y el riesgo de sus inversiones en compañías eléctricas y trenes..$^{30}$ En general, la diplomacia británica reflejaba en su postura y acciones la preocupación por los intereses imperiales en riesgo, a su ver débilmente defendidos por el gobierno estadounidense, al que se había confiado tal responsabilidad en reconocimiento de su ascendiente continental. ${ }^{31}$ Los problemas y presiones por motivos materiales y económicos fueron sin duda importantes aunque no determinantes de la exclusión de acuerdo con el propio Pani, si bien no dejaron de representar un coro en favor de la represalia contra la revolución mexicana liderada por Carranza. ${ }^{32}$ A finales de julio de 1919, desde París, Cándido Aguilar le informaba al presidente mexicano, quien además era su suegro, del acuerdo entre Francia, Gran Bretaña

30 Robert Borden a David Lloyd George, París, 8 de marzo de 1919 y Robert Borden a Arthur James Balfour, ANRU, FO, 608/174/13. Esta gestión fue propiciada por el informe y urgente petición intervencionista que E. R. Peacock, miembro en representación de Canadá del comité general para la representación de los intereses británicos en México, había dirigido previamente a R. Borden desde Londres, el 1o de marzo de 1919. ANRU, FO, 608/174/13.

31 Cunard Cummins insistía en ello ante al secretario de Estado para los Asuntos Exteriores, México, 24 de enero de 1919, ANRU, FO, 608, "Responsibility of U. S. Govt. for losses of British Subjects in Mexico".

32 De acuerdo con Pani, quien habría tenido conversaciones de importancia con miembros de la comisión estadounidense a la Conferencia de Paz, la campaña antimexicana de Doheny había logrado llamar la atención pero no influido ni determinado nada en relación con México. PAni, Cuestiones diversas contenidas en 44 cartas, pp. 19-21. Este tipo de casos, en cierto modo comparables al del autosecuestro del agente consular estadounidense en México William O. Jenkins, terminaban por ser abanderados por la oposición republicana no obstante sus controvertidos antecedentes. BERG, Wilson, pp. 660-661, 667; Lazo, "Lansing, Wilson, and the Jenkins", pp. 181-183. 
y Estados Unidos de dejar a esta última potencia, por respeto a la Doctrina Monroe, dirigir

Una nota al gobierno mexicano invitándolo a que se nombre una comisión mixta para fijar las cantidades que México debe pagar por daños causados por la revolución, y en caso de que México no acepte el plazo y gestiones del representante de las tres potencias obligarán a México por medio de la fuerza a cumplir sus deberes internacionales. ${ }^{33}$

Carranza simplemente instruyó a Pani de informar al gobierno francés, por no reconocer la planteada intermediación estadounidense de un grupo de naciones, que no habría problema en integrar tal comisión mixta según lo previsto en noviembre de $1917 .{ }^{34}$ El tema no volvió a tocarse en París.

El principal problema en torno a México tenía que ver con la trayectoria conspirativa antiestadounidense del propio Carranza, emprendida hacia 1915 y profundizada a partir de 1917, aprovechando relaciones con minorías étnicas -de color y mexicanas- propensas a la rebelión interna en los estados fronterizos, y profundizada de la mano de servicios de espionaje y agentes comerciales y diplomáticos de potencias en expansión (Japón) y enemigas encubiertas (Alemania) de Estados Unidos en el marco de la gran guerra. ${ }^{35}$ Las conclusiones a las que hace apenas diez

33 SÁENZ, La política internacional, p. 78.

${ }^{34}$ SÁenz, La politica internacional, p. 78.

35 Véase Schuler, Secret Wars, pp. 168-228. Alfonso Taracena ya había escrito al respecto: "Don Venustiano siempre ha abrigado un profundo resentimiento contra los Estados Unidos del Norte y, cuando las proposiciones de Zimmerman, llegó a acariciar la esperanza de una revancha por lo del 47 [...] Quienes lo conocen en la intimidad saben que considera un deber de todo mexicano y patriota hacer cuanto sea posible por vengar el ultraje. Desde que comenzó a regir los destinos del país, esperaba que estallara en los Estados Unidos una guerra civil en la que México se sumaría a los estados del sur. Esta guerra civil opinaba que sería continuación de la anterior, o el resultado 
años llegó Friedrich E. Schuler a este respecto han terminado por desplazar la idea de que todo se había tratado por completo de un estratégico y magistral bluff de Carranza que no habría podido ir más allá; 36 lo mismo que aquellas versiones victimistas que apuntaban a una injusta y desagradable marginación de México de la sociedad de naciones pacíficas y civilizadas. Para los servicios de inteligencia angloestadounidenses, como cuidadosamente demuestra Schuler, Carranza y algunos de sus representantes en el exterior a los que no se perdía de vista (Cándido Aguilar e Isidro Fabela, los de mayor confianza del jefe revolucionario) ampliarían el espectro de conspiración exterior a Sudamérica y Europa como reacción a viejos resentimientos, tales como la pérdida de territorio en el siglo pasado, y a los recientes y sugerentes sucesos relacionados con Tampico, Veracruz y la expedición punitiva. Por si fuera poco, Carranza seguiría adelante en sus preparativos de abastecimiento militar (equipo e industria) y en su campaña antiestadounidense a lo largo de una Conferencia de Paz que pretendía colapsara y confrontara a alemanes, japoneses e italianos contra la principal potencia americana. ${ }^{37}$ Con la

del odio de razas, entre negros y blancos, en la que los mexicanos tomarían el partido de los primeros o, por último, el estallido de la lucha entre trabajadores y capitalistas. En todas estas circunstancias, don Venustiano esperaba que México recuperaría a la postre el territorio perdido". TARACENA, La verdadera revolución, p. 210.

36 Véase KaTz, La guerra secreta, pp. 585-586; MeYer, México y los Estados Unidos, pp. 211-226; STReEter, Central America and the treaty of Versailles, pp. 55-59; Corzo Ramírez, González Sierra y Skerritt, ... Nunca un desleal, pp. 165-174, 181-185.

${ }^{37}$ Cunard Cummins, el agente británico en activo en México, advertía sobre la ansiedad creciente entre la opinión pública y el gobierno propiciada por la actitud intransigente y arriesgada del presidente Carranza: "Tuve conocimiento, por medio de una fuente incuestionable, que se han celebrado reuniones secretas entre personas influyentes en las que se han mencionado y apoyado calurosamente mis puntos de vista y se ha dicho que su cumplimiento es vital para México. Se coincidió en que la actitud de Carranza está colocando el destino de México a merced de Estados Unidos y también se afirmó que, en última 
intención específica de debilitar el principal proyecto internacional de Wilson, la Sociedad o Liga de las Naciones, el propio Carranza no solo buscó erosionar insistentemente su figura y pertinencia entre las naciones latinoamericanas con advertencias sobre el lugar de la Doctrina Monroe en el proyecto, sino que esbozó y ganó adeptos europeos y americanos ${ }^{38}$ para montar, nada más y nada menos, que una competitiva Liga Latina. ${ }^{39}$ "El verdadero líder de esta campaña -precisa Schuler- siguió siendo el presidente Carranza [...]". ${ }^{40}$ Todo terminó precipitadamente en la primera mitad de 1920, apenas tres meses después de inaugurada la Sociedad de Naciones:

Durante la noche, el actor más entusiasta en la alianza antiestadounidense, Venustiano Carranza fue arrancado del escenario de la historia. En abril de 1920, fue asesinado en respuesta a la imposición de un sucesor presidencial escogido por él. La cooperación multinacional contra los Estados Unidos había experimentado una fuerte sacudida. Y sin embargo, ni la red ni la cooperación colapsaron. ${ }^{41}$

instancia, México pagaría la obstinación de Carranza con sangre, es decir con una invasión estadounidense". ANRU, FO, 608/174/14, "Representation of Mexico at Peace Conference and in League of Nations".

${ }^{38}$ Con la singular excepción de Guatemala, que había sufrido hasta entonces la amenaza indirecta de Alemania que también buscaba la simpatía de México y El Salvador planteándoles una recuperación territorial a costa de la primera por ser indiferente a la lucha de los imperios centrales. STREETER, Central America and the treaty of Versailles, pp. 57-58.

39 Planteada en oposición a la doctrina Monroe y, por consiguiente, a la Sociedad de Naciones, estuvieron dispuestos a participar en una primera conferencia: Argentina, Colombia, Costa Rica, Chile, Ecuador, El Salvador, México y Paraguay; Alemania, España y Venezuela la apoyarían indirectamente. Véase Schuler, Secret Wars, pp. 229-288.

40 "The true leader of this effort remained President Carranza..." Schuler, Secret Wars, p. 280.

${ }^{41}$ En su idioma original: "Overnight, the most enthusiastic actor in the anti-U.S. alliance, Venustiano Carranza, was ripped off the stage of history. In April 1920, he was assassinated in response to imposing a hand-selected 
En México, Carranza jamás cambió su opinión respecto de la Sociedad de Naciones. ${ }^{42}$

Haciendo un buen uso de las conclusiones de Schuler, quien no se ocupa particularmente de la exclusión de México de la Sociedad de Naciones, ¿no había el propio Carranza tomado esta decisión y actuado con este particular propósito como parte de su estrategia de descrédito a la obra internacional de los enemigos de la revolución mexicana? Tan pronto fue esbozada la futura organización y su Pacto constitutivo, Carranza hizo declaraciones ${ }^{43}$ a lo largo de 1919 que en compañía de sus actos subversivos representaban un rechazo claro a la paz en desarrollo y a la propia derrota de Alemania, su principal referente de rechazo a las potencias anglosajonas. Con motivo de las representaciones estadounidenses por la desaparición del súbdito inglés William Benton:

La doctrina Monroe constituye un protectorado arbitrario, impuesto sobre los pueblos que no lo han solicitado ni tampoco lo necesitan. La doctrina de Monroe no es recíproca y por consiguiente es injusta. Si se cree necesario aplicarla a las repúblicas hispanoamericanas podía aplicarse igualmente al mundo entero. Se trata de una especie de tutela sobre la América española que no debiera existir bajo ninguna excusa. El presidente Wilson se expresó en el mismo sentido que yo cuando recibió a los periodistas mexicanos. Podrían enumerarse los casos en que la aplicación de la doctrina Monroe ha

presidential successor. The multinational cooperation against the United States had experienced a strong jolt. And yet neither the network nor the cooperation collapsed". Schuler, Secret Wars, pp. 283-284.

42 Schuler, Secret Wars, p. 274.

${ }^{43}$ Estas habían prácticamente iniciado en 1917, en forma escrita y verbal, por medio de la nueva Constitución y su artículo sobre política exterior (27), así como en discursos y ponencias públicas oficiales que hacían suyo el espíritu de las doctrinas Calvo y Drago. Véase la nota 16. 
causado dificultades en las repúblicas hispanoamericanas. Estamos en el caso análogo a alguien que se le ofreciera un favor y lo rechazara, pero a pesar de esto se le impusiera la aceptación de ese favor, que no necesita. ${ }^{44}$

\section{Ese mismo año ante el Congreso:}

Como en la Conferencia de Paz de París se trató sobre la aceptación de la doctrina Monroe, el gobierno de México se vio en el caso de declarar públicamente y de notificar oficialmente a los gobiernos amigos que México no había reconocido ni reconocería esa doctrina, puesto que ella establece, sin la voluntad de todos los pueblos de América, un criterio y una situación que no se les ha consultado y por lo mismo esa doctrina ataca la soberanía e independencia de México y constituiría sobre todas las naciones de América una tutela forzosa. ${ }^{45}$

Pero antes, a mediados de abril de 1919, fue el propio Wilson, con el respaldo inglés, quien tomó la decisión más práctica-o sabia, en sus palabras-46 en relación con la cuestión mexicana: borrarlo de la lista de países neutrales que habrían de ser invitados en condiciones de igualdad con las potencias aliadas a la naciente organización internacional, ${ }^{47}$ dejando a los propios mexicanos la decisión de solicitar su ingreso y, claro está, de negociarlo más adelante, no obstante que la medida mereció críticas del

${ }_{44}$ Tomado de Serrano Migallón, Isidro Fabela, p. 85.

45 Tomado de Serrano Migallón, Isidro Fabela, p. 85.

46 Se refirió así a la posibilidad, expresada a David Hunter Miller el 15 de abril de 1919, de no extender una invitación a ingresar en la Sociedad de Naciones a Costa Rica, México y Santo Domingo: "Creo que en general sería pruedente no incluir ninguno de estos tres Estados en la invitación”. Miller, My Diary at the Conference, p. 324a.

47 Walters, Historia de la Sociedad de Naciones, pp. 53-54. 
secretario de Estado Robert Lansing. ${ }^{48}$ De otro modo, me atrevo igualmente a afirmar, se le habría brindado a México el acceso a una tribuna internacional inmerecida y mucho menos apreciada, algo equivalente a invitar al aguafiestas. Los reclamos y exigencias en favor de un reconocimiento pleno de la soberanía mexicana representados por Carranza habían perdido toda su fuerza por su aproximación a Alemania y su posterior derrota, por lo que el trato que recibiría la revolución mexicana de parte de las potencias de Versalles iría así en natural contrasentido.

\section{ORGULLO Y RETRAIMIENTO}

Dos meses antes de su primera Asamblea en noviembre de 1920, Carranza, teniendo al Congreso como público, desairaría oficialmente cualquier forma posible de relación con la Sociedad de Naciones, en el entendido de que: "no ha hecho ni hará gestión alguna para ingresar a esa sociedad internacional, toda vez que las bases que la sustentan no establecen ni en cuanto a su organización, ni en cuanto a su funcionamiento, una perfecta igualdad para todas las naciones y todas las razas [...]". ${ }^{49}$ El epílogo racial hacía eco de las demandas insatisfechas de Japón frente a los artífices del nuevo orden, otra potencia predilecta de Carranza en amenazante expansión en el Pacífico americano. ${ }^{50}$

${ }_{48}$ David Hunter Miller anotó en uno de sus memoranda de consulta al presidente Wilson a mediados de abril de 1919: "Lord Robert Cecil se opone ampliamente a la inclusión de México. El Sr. Lasing me expresó una opinión favorable a la invitación. Considero que como el actual gobierno de México no ha sido reconocido ni por Gran Bretaña ni Francia, una invitación supondría, en mi opinión, un reconocimiento de ese gobierno por parte de estas naciones". Miller, My Diary at the Conference, p. 308.

49 Tomado de Perkins, A History of the Monroe Doctrine, p. 326.

${ }^{50}$ En realidad, se trató de una solicitud muy concreta previa la redacción final del Pacto: agregar en su preámbulo el principio de igualdad entre las naciones, el cual terminaría chocando con las leyes inmigratorias de Estados Unidos, Australia y Nueva Zelanda para el Asia oriental. Sobre el desencuentro 
El legado de Carranza tras su violenta muerte en mayo de 1920 comprendió una postura orgullosa pero sobre todo práctica y realista frente a la Sociedad de Naciones, referente bochornoso de su marginación internacional, pero de ningún modo responsable de ello como sí lo fueron Wilson, Cecil, Bourgeois -sin olvidar a Doheny- y el propio Carranza. Su salida de escena no cambió nada. El sostenimiento de esta decisión por los gobiernos de ascendencia sonorense entre De la Huerta y Ortiz Rubio cubrió toda una década, sin duda benéfica para estabilizar el régimen revolucionario y resolver o canalizar los principales problemas de México con el exterior. Los reconocimientos internacionales al régimen posrevolucionario, especialmente los de Estados Unidos y Gran Bretaña, representaron los principales avances en este complicado proceso de normalización, donde Ginebra no pudo ubicarse sino al final del mismo en razón de la perceptible -y principal- influencia británica sobre la Sociedad de Naciones. La paradójica ausencia estadounidense en la misma no podía hacerla menos atractiva para México, ni el restablecimiento de relaciones entre ambos haber propiciado una colaboración más temprana. La Sociedad de Naciones era apreciada justamente como lo que políticamente fue durante estos primeros años: una institución sostenida por Francia y Gran Bretaña para hacer valer las condiciones de paz y el orden de posguerra en Europa con apoyo de una numerosa sociedad de miembros internacionales que podrían reconocerse allí como naciones civilizadas y en plenitud. ${ }^{51}$ En un estado prudente de autocon-

\footnotetext{
japonés con el proyecto societario, véase MacMillan, París, 1919, pp. 393411; Walters, Historia de la Sociedad de Naciones, pp. 76-77; Ambrosius, Woodrow Wilson, pp. 120-122.

${ }^{51}$ En el caso de algunas naciones latinoamericanas, en especial las del área central y caribeña, tal membresía suponía ciertamente un reconocimiento a su soberanía y una garantía de afianzamiento de sus gobiernos y de trato igualitario en el medio internacional. Véanse las obras más acabadas en la materia: Fischer, Die Souveränität der Schwachen; WeHrLI, "États latinoaméricains".
} 
servación y de reluctancia respecto del imperialismo podría entenderse muy bien que la revolución mexicana no mostrara ninguna inquietud por la organización ginebrina; es fácil imaginarlo y advertir en ello una hipotética situación incómoda. El ingreso de Alemania en la Sociedad de Naciones, presenciado desde la misión de México por Pascual Ortiz Rubio, entonces su jefe, ${ }^{52}$ supuso un cambio cualitativo que dio pauta a acuerdos y entendimientos de distención entre las potencias europeas, los cuales impactaron positivamente a Ginebra y renovaron su atractivo. Además de que daba muestra de universalismo y robustecimiento, la Sociedad de Naciones se perfilaba notoriamente mediante una constelación de organismos permanentes de naturaleza técnica, jurídica y social que conseguirían atraer la atención de algunos actores destacados de la diplomacia mexicana. Pero esto no ocurrió tempranamente, como una serie de gestiones internacionales que contribuyeron a despejar un poco el ambiente que había dejado allí el episodio de exclusión y rechazo mutuo entre México y las potencias anglosajonas. El tema se había convertido, públicamente, en uno difícil de dignidad nacional, así que no hubo demasiadas voces en todo este tiempo que plantearan reconsiderar una colaboración permanente con la Sociedad de Naciones. Quizá esta postura libre de críticas resultaba igualmente un acierto estratégico en cuanto que no exponía al régimen posrevolucionario al escrutinio público internacional en momentos complicados de negociación de daños $\mathrm{y}$ afectaciones pasados y futuros con las potencias, o bien, de propiciar regionalmente la revolución ${ }^{53}$ o de enfrentarse con la Iglesia católica, lo cual fue efectivamente denunciado en Ginebra por una solidaria feligresía internacional. ${ }^{54}$

52 Ortiz Rubio, Memorias, pp. 124-131.

53 Palacios, América del Sur, pp. 189-195, 225-228.

54 ASDN, Sección política, c. R 1839, exp. 2322: "Situation des catholiques au Mexique. Protestations et résolutions diverses”. 
En paralelo, una serie importante de gestiones internacionales vendrían a desarrollarse a lo largo de la década de 1920, con el propósito común de animar a México a solicitar su ingreso en la Sociedad de Naciones. ${ }^{55}$ Todas ellas ofrecerían ciertas garantías respecto al voto de la Asamblea, pero ninguna logró entender adecuadamente los impedimentos que operaban de forma negativa frente a esta posibilidad en el medio gubernamental mexicano y que bien podrían reducirse a tres, ninguno de ellos libre de imprecisiones: la Sociedad de Naciones, en particular, había ofendido gravemente al país con su exclusión; la organización hacía valer la Doctrina Monroe en el continente americano; pero no servía sino a los intereses de las principales potencias europeas en ese mismo contexto. Aclarar todo esto fue muy complicado en su tiempo e indudablemente prevalece confusamente en el nuestro. Pero al final, gracias en parte a estas gestiones, y muy especialmente a la visita que llevó a cabo en México Julián Nogueira, ${ }^{56}$ funcionario uruguayo de la Oficina para América Latina de la Sociedad de Naciones (única en su tipo y de especial atractivo para los especialistas), ${ }^{57}$ se fue aclarando que la Sociedad de Naciones nada tenía que ver con la medida de exclusión pues ni siquiera había abierto sus puertas cuando ocurrió el agravio; que el artículo 21 del Pacto, donde se hacía referencia a la Doctrina Monroe como una inteligencia regional, ya había sido interpretado jurídicamente por la propia organización dejando a salvo todos los derechos de los miembros latinoamericanos, ${ }^{58}$ y que tal mención había sido

${ }^{55}$ Un número importante de estas iniciativas diplomáticas son recopiladas en Díaz y Martini, Relaciones diplomáticas México-España, pp. 256-280; FALcón Salgado, "México en la Sociedad de Naciones”, pp. 31-37 y Herrera LEón, "Proceso de integración”, pp. 57-75.

56 Herrera León, "La Sociedad de Naciones y el problema”.

57 Sobre el Bureau de l'Amérique latine véanse los trabajos de WeHRLI, "Créer et maintenir l'intérêt” y “États latino-américains”, pp. 196-208.

58 Véase la nota 2. 
solicitada extraordinariamente por el presidente Wilson para lograr el ingreso de su país en la organización, algo que entonces no ocurrió, pero que bien podría presentarse en el futuro, de allí que esta particular reserva estadounidense al Pacto debiera permanecer allí; y finalmente, que el interés de las potencias europeas referentes de la Sociedad de Naciones, Gran Bretaña y Francia, coincidía con el de la organización, la cual seguiría buscando universalizarse mediante un número mayor de miembros asociados.

No obstante el desafortunado desenlace de esta serie de iniciativas amistosas, ${ }^{59}$ la mayoría de ellas concebidas por el grupo de países latinoamericanos presentes en Ginebra, su planteamiento y desarrollo dio pie a recurrentes discusiones sobre una posible colaboración eventual y selectiva en congresos internacionales a los que México era invitado y con organismos y organizaciones ginebrinos que ponían en él especial interés, tales como la Oficina Internacional del Trabajo y el Instituto Internacional de Cooperación Intelectual. ${ }^{6}$

\section{LA IMPOSIBLE INCURSIÓN GRADUAL Y SELECTIVA: UN INGRESO NEGOCIADO}

Al mediar la década de 1920, México podía dar por concluida la lucha revolucionaria y su estabilización se había favorecido de la obra de pacificación interna, regeneración económica y restablecimiento constitucional emprendidos por el gobierno de Álvaro Obregón (1920-1924). Este proceso de normalización e institucionalización del régimen posrevolucionario supuso la reconstrucción gradual de relaciones con el exterior, empezando por el ámbito continental hasta llegar a acuerdos

59 La documentación diplomática en cuestión está agrupada en el Archivo Histórico Diplomático “Genaro Estrada” de la Secretaría de Relaciones Exteriores (en adelante AHGE-SRE), leg. LE 2171.

60 Véanse de mi autoría “México y la oIT” y "México y el IICI”. 
importantes con Estados Unidos -y eventualmente con otras potencias de Europa- con el reconocimiento de daños sobre personas y bienes y su indemnización, así también como con la aceptación de la no retroactividad del artículo 27 de la Constitución, que había pesado como una amenaza sobre concesiones petroleras estadounidenses, inglesas y holandesas. Pero este era solo el comienzo y la regularización internacional siguió supeditada a la solución aún no completada del cúmulo de problemas relacionados con la afectación de intereses extranjeros. La crisis fiscal profundizada por la rebelión delahuertista obligó al gobierno de Plutarco Elías Calles (1924-1928) a hacer nuevos ajustes legales a contracorriente de los acuerdos de Bucareli alcanzados por Obregón, generando una nueva crisis diplomática con Estados Unidos. Los acuerdos Calles-Morrow de 1927 devolvieron la calma mediante la preservación de los derechos de explotación de inversionistas estadounidenses anteriores a la Revolución, un problema contenido pero latente aún durante una década más.

Por otra parte y en otro orden de cosas, el régimen posrevolucionario ganaría considerable confianza una vez que se viera en la necesidad de romper relaciones con la Unión Soviética en 1930, despejando con ello los temores de bolchevización que despertaban las políticas de carácter social, su enfrentamiento con la Iglesia y el respaldo que concedía a formaciones nacionalistas y antiimperialistas de la región. ${ }^{61}$ El lugar de México en el mundo podía ser otro, tal como lo fueron sugiriendo los reconocimientos diplomáticos de Estados Unidos, Alemania, Francia y Gran Bretaña. ${ }^{62}$ También su lugar en el continente podía serlo, y la maduración del régimen revolucionario, con el atractivo de sus logros de corte nacionalista, le devolvía su anterior ascendente entre las principales potencias regionales

\footnotetext{
61 Véase SPENCER, “Forjando una nación posrevolucionaria”, pp. 313-350.

62 Sánchez Andrés, México en el siglo XX, pp. 26-28.
} 
y le permitía involucrarse en la resolución de los conflictos del Chaco y Leticia. ${ }^{63}$

Estos también fueron años de modernización y profesionalización del servicio exterior mexicano mediante una serie de acciones impulsadas por Alberto J. Pani a su paso por la cancillería: un reclutamiento mejor cuidado y la formalización de la carrera diplomática; una reorganización administrativa para el mejor aprovechamiento de recursos en aras de una mayor visibilidad exterior; $y$, finalmente, una reestructuración interna para garantizar un buen seguimiento para distintos ámbitos de interacción y la toma de decisiones. ${ }^{64}$ La política exterior mexicana buscó remarcar con mayor éxito su carácter autodefensivo a lo largo de estos años, que fueron propicios para proyectar una identidad renovada y estable en el espacio exterior, fortalecida con un meditado cuerpo doctrinario que terminaría por robustecer notoriamente Genaro Estrada al cambio de década. ${ }^{65}$ Este vendría a ser el cauce ideal de las relaciones de México con el mundo y sus nuevas organizaciones.

Fue el propio Estrada, a quien se le reconoce una notoria influencia en la cancillería desde mediados de la década de 1920, quien impulsó una vinculación permanente con Ginebra ante la creación de redes y vínculos con el funcionariado ginebrino y su colaboración en los proyectos científico e intelectual originados por Alfonso Reyes en 1926 y que condujeron a la colaboración con el Instituto Internacional de Cooperación Intelectual con sede en París, dependiente de la Sociedad de Naciones. ${ }^{66}$ Estrada buscaría elevar a una relación estable -pero aún marginal respecto de la Sociedad de Naciones- las atenciones y trato cordial con México iniciado años atrás por Albert

63 Véase Palacios, América del Sur, pp. 267-300 y Herrera León, La política mexicana en la Socieda de Naciones.

${ }^{64}$ Savarino Roggero, México e Italia, pp. 23-25.

${ }^{65}$ SÁnchez Andrés, "México y la crisis", pp. 135-136.

66 Véase Estrada, La diplomacia en acción. 
Thomas, el director de la Oficina Internacional del Trabajo. El propósito de un involucramiento gradual y selectivo con el espacio multilateral ginebrino decidió el envío de un representante permanente en la figura de un observador, quien en términos prácticos haría las veces de un negociador frente a esas dos principales organizaciones internacionales. Lo cierto es que la integración gradual y selectiva buscada por Estrada no prosperó y todos los acuerdos e intentos ante la institución laboral a cargo de Thomas encontraron una oposición discreta pero firme en la organización central a cargo de Eric Drummond, naturalmente preocupado por la tendencia fragmentaria y selectiva de la política mexicana hacia Ginebra y la interpretación que podría hacerse de la misma por los miembros de la Sociedad de Naciones y futuros postulantes.

El presidente Ortiz Rubio, con una experiencia diplomática previa en Alemania y Brasil, naciones que respectivamente habían ingresado en la Sociedad tardíamente, pasando por una negociación aún más complicada, caso de la primera; y que al optar por retirarse de la misma, caso de la segunda, habían permanecido en la Organización Internacional del Trabajo y otras instancias multilaterales, por lo que ciertamente cupo explorar todas las posibilidades de involucramiento con Ginebra, incluida la Corte Permanente de Justicia Internacional. Salvador Martínez de Alva, sucesor de Antonio Castro Leal ${ }^{67}$

67 Antonio Castro Leal había pasado enfermo gran parte de su misión, y si bien había sido formalmente recibido por la Sociedad de Naciones bajo el inusual título de "observador permanente", contó con escasa atención de parte del funcionariado internacional ginebrino. Tal como lo expresó en el momento de su partida al cónsul estadounidense en Ginebra, Prentiss B. Gilbert, Castro Leal interpretaba su retiro como la pérdida de interés de su gobierno en una colaboración futura con la Sociedad de Naciones. Por el contrario, se trataba de una decisión tomada con base en los escasos resultados alcanzados hasta ese momento. Prentiss B. Gilbert al Departamento de Estado, informe confidencial núm. 124, "Mexico in Geneva, with notes on certain technical and political situations respecting states non-members of the League", Ginebra, 
en el puesto de observador de México en Ginebra, intentó sin éxito prácticamente todo ante la Organización Internacional del Trabajo, desgastando, incluso, la buena relación con Thomas y con la Sección Jurídica de la Sociedad de Naciones. ${ }^{68}$ Martínez de Alva fue instruido para tratar directamente con el secretario general de la Sociedad las condiciones de ingreso en esa y, en automático, a la constelación de organismos internacionales vinculados. Drummond no solo se mostró accesible sino que orquestó acciones de desagravio que involucraron a todas las potencias internacionales integrantes de su Consejo, Inglaterra y Francia entre ellas. La diplomacia republicana española, no cabe duda, contribuyó espontáneamente a generar un ambiente favorable a la incorporación mexicana, pero lo importante se decidió en las oficinas de la Secretaría General, quizá también el acceso inmediato -sin esperar turno-que tuvo México al Consejo de la Sociedad de Naciones (1932-1935). La descripción ceremonial del mea culpa que las potencias internacionales de la Sociedad de Naciones concedieron a México para celebrar su llegada encuentra un espacio importante en la historiografía tradicional sobre el tema. Pero sobre lo que no existe documentación es sobre el verdadero ánimo de México frente a la titánica obra societaria a través del multilateralismo, una cuestión a veces difícil de entender para los propios protagonistas del concierto a diversos planos concebido por un sistema internacional que era más que un baluarte de un statu quo y de unas condiciones de paz, motivo, sin embargo, por el que sería temporalmente replegado e interrumpido. El caso mexicano sería uno de difícil equiparación

24 de junio de 1931, NARA, DS, c. 5282, League of Nations/Membership RG 59/500.C001/549.

68 Prentiss B. Gilbert al Departamento de Estado, informe confidencial núm. 124, "Mexico in Geneva, with notes on certain technical and political situations respecting states non-members of the League”, Ginebra, 24 de junio de 1931, NARA, DS, c. 5282, League of Nations/Membership RG 59/500.C001/549. Véase también Herrera León, “México y la oiT”. 
entre el convencimiento o determinación de un gobierno y lo que entendemos por interés nacional, pues el atractivo de Ginebra pareció diluirse junto con el gobierno de Ortiz Rubio y solo la permanencia obligada de dos años previo anuncio de retiro (de diciembre de 1932) dio lugar a una reflexión final más meditada respecto a la permanencia mexicana en Ginebra.

\section{SIGNIFICADO: UN MODO DE CONCLUSIÓN}

El centenario de la creación y puesta en marcha de la Sociedad de Naciones dará lugar a muy variadas y serias reflexiones sobre su historia y legado. Un número reducido aunque valioso corresponderá al paso y desempeño en ella de los que fueron sus miembros latinoamericanos, hasta hace muy poco atendidos debidamente por la historiografía. Esta reflexión se empieza a hacer igualmente en sentido inverso, para especificar el lugar y alcance en esta subregión no compacta del internacionalismo ginebrino, sus influencias y aportes. Lo indicado, en el caso de México, asociado desde 1931 y aún presente en el momento de liquidación formal de esta primera gran organización internacional en 1946, es pensar un poco en la situación incómoda e inquietante en que se encontró por espacio de una década, la de 1920, sin la cual sería aún más difícil comprender el modo y motivaciones que terminaron conduciendo a este país a Ginebra, quizá muy a pesar suyo en razón de los sentimientos en torno a esta idea. Pero también importarán las motivaciones de la propia Ginebra y sus representantes internacionales frente al país revolucionario ausente.

Aunque no modificado en esencia, que es el propicio para la interacción y trato soberano entre los Estados-nación aún vigente y determinante en nuestro tiempo, el sistema internacional edificado con el Palacio de la Paz, frente al lago Leman, observó importantes variaciones o extensiones en nuevos escenarios o planos de desarrollo y resolución para proyectos y problemas 
de común interés. La esfera multilateral ha prevalecido en pie sobre los cimientos imperfectos colocados cien años atrás y su perfeccionamiento solo puede ser sugerido por la comprensión de aquello que no dio resultado y volvió a fallar en el marco de otros periodos de crisis internacional que caracterizaron al siglo xx en su plano multilateral. Cierta atención especial tendría que ser puesta en aquellos actores disonantes y políticamente excéntricos y molestos en este ámbito, como México, respecto de los preocupantes y mal atendidos desmoronamientos de la Paz de Versalles. Ojalá que estos centenarios temáticos relacionados con la política y diplomacia mexicanas en la Sociedad de Naciones lleguen a ser algo más que una ocasión para la celebración de un heroísmo carente de significado.

\section{SIGLAS Y REFERENCIAS}

AHGE-SRE Archivo Histórico "Genaro Estrada” de la Secretaría de Relaciones Exteriores, Ciudad de México, México.

ANRU, CAB Archivos Nacionales del Reino Unido, Cabinet Papers, Kew, Inglaterra.

ANRU, FO Archivos Nacionales del Reino Unido, Archivos del Foreing Office, Kew, Inglaterra.

ASDN Archivo de la Sociedad de Naciones, Ginebra, Suiza.

NARA, DS National Archives and Records Administration, Departament of State, Washington, Estados Unidos.

Aguilar Monteverde, Alonso (comp.), Narciso Bassols, pensamiento y acción, México, Fondo de Cultura Económica, 1995.

Ambrosius, Lloyd E., Woodrow Wilson and the American Diplomatic Tradition. The Treaty Fight in Perspective, Cambridge, Cambridge University Press, 1987.

Berg, A. Scott, Wilson, Nueva York, Putnam, 2013.

Cárdenas, Cuauhtémoc, Cárdenas por Cárdenas, México, Debate, 2016.

CARR, Edward Hallett, La crisis de los veinte años (1919-1939). Una introducción al estudio de las relaciones internacionales, Madrid, Catarata, 2004. 
Carrillo Reveles, Veremundo, "México en la Unión de las Repúblicas Americanas. El panamericanismo y la política exterior mexicana, 1889-1942”, tesis de doctorado en historia, Ciudad de México, El Colegio de México, 2018.

Corzo Ramírez, Ricardo, José G. González Sierra y David A. Skerritt, ...Nunca un desleal: Cándido Aguilar (1889-1960), México, El Colegio de México, Gobierno del Estado de Veracruz, 1986.

De la Pedraja y Muñoz, Daniel, "La admisión de los Estados de América Latina en la Sociedad de las Naciones: el caso de México”, en Revista Mexicana de Ciencias Políticas (jul.-sept. 1969), pp. 387-395.

DíAz, Luis Miguel, Historia de las relaciones internacionales de México, México, Porrúa, 1983.

Díaz, Luis Miguel y Jaime G. Martini (comps.), Relaciones diplomáticas México-España (1821-1977), México, Porrúa, 1977.

Echeverría Álvarez, Luis, El sistema de equilibrio de poder y la Sociedad de Naciones: ensayo jurídico-político, México, Espiga, 1945.

Estrada, Genaro, La diplomacia en acción, México, Secretaría de Relaciones Exteriores, 1987.

Fabela, Isidro, Cartas al presidente Cárdenas. La política internacional del presidente Cárdenas, México, Instituto de Cultura Mexiquense, El Colegio de México, 1994.

Falcón SAlgado, Julieta Rosario, "El ingreso y la participación de México en la Sociedad de Naciones. Las contribuciones diplomáticas de México frente al segundo conflicto italo-etíope", tesis de licenciatura en relaciones internacionales, México, El Colegio de México, 2011.

Fischer, Thomas, Die Souveränität der Schwachen: Lateinamerika und der Völkerbund, 1920-1936, Stuttgart, Franz Steiner Verlag, 2012.

García Gutiérrez, Rosa, "La pluma y la acción: la labor diplomática de Genaro Estrada”, en Sola Ayape (coord.), 2016, pp. 105-135.

Gilly, Adolfo y Mario Ojeda Revah (coords.), Lázaro Cárdenas: iconografía, Madrid, Secretaría de Cultura del Gobierno de Michoacán, Turner, 2007. 
Guillén, Fedro, Fabela y su tiempo: España, Cárdenas, Roosevelt, México, Centro de Estudios Históricos del Agrarismo en México de la Secretaría de la Reforma Agraria, 1981.

Herrera, Octavio y Arturo Santa Cruz, América del Norte, México, Secretaría de Relaciones Exteriores, 2011.

Herrera León, Fabián, "El paso de México por la Sociedad de Naciones; la construcción retórica de una trayectoria y destino internacionales", en HERRERA LEÓN y WeHRLI (coords.), 2019, pp. 325-354.

Herrera León, Fabián, La política mexicana en la Sociedad de Naciones ante la Guerra del Chaco y el conflicto de Leticia, 1932-1935, México, Dirección General del Acervo Histórico Diplomático (Colección Latinoamericana), 2009.

Herrera León, Fabián, "La Sociedad de Naciones y el problema del distanciamiento mexicano: la misión internacional de Julián Nogueira en México, agosto-septiembre de 1923", en Tzintzun. Revista de Estudios Históricos, 57 (ene.-jun. 2013), pp. 125-153.

Herrera León, Fabián, "Mexico and its 'Defense' of Ethiopia at the League of Nations”, en McPherson y Wehrli, 2015, pp. 49-62.

Herrera León, Fabián, "México y el Instituto Internacional de Cooperación Intelectual, 1926-1939”, en Tzintzun. Revista de Estudios Históricos, 49 (ene.jun. 2009), pp. 169-200.

Herrera León, Fabián, "México y la Ginebra internacional de entreguerras, 1919-1939”, en HERrera LeÓn, 2018, pp. 15-32.

Herrera León, Fabián, "México y la Organización Internacional del Trabajo: los orígenes de una relación, 1919-1931”, en Foro Internacional, LI: 2, 204 (abr.-jun. 2011), pp. 336-355.

Herrera León, Fabián, México y la Sociedad de Naciones. Una antología documental, Morelia, Archivo General de la Nación, Secretaría de Relaciones Exteriores, Dirección General del Acervo Histórico Diplomático, Universidad Michoacana de San Nicolás de Hidalgo, 2018.

Herrera León, Fabián, "Proceso de integración de México en la Sociedad de Naciones (1919-1931)", tesis de licenciatura en historia, Morelia, Universidad Michoacana de San Nicolás de Hidalgo, 2002. 
Herrera León, Fabián y Yannick Wehrli (coords.), América Latina y el internacionalismo ginebrino de entreguerras: implicaciones y resonancias, Ciudad de México, Secretaría de Relaciones Exteriores, Dirección General del Acervo Histórico Diplomático, 2019.

KaTZ, Friedrich, La guerra secreta en México, México, Ediciones Era, 1998.

LAzo, Dimitri D., "Lansing, Wilson, and the Jenkins Incident", en Diplomatic History, 22: 98 (abr. 1998), pp. 177-198.

León y González, Samuel (coord.), El cardenismo, 1932-1940, México, Fondo de Cultura Económica, 2010.

López-Bassols, Hermilo, "México en la encrucijada de su historia: génesis y praxis de una política exterior”, en Sola Ayape (coord.), 2016, pp. 63-89.

MacMillan, Margaret, París, 1919. Seis meses que cambiaron al mundo, Barcelona, Tusquets, 2005.

Márquez Muñoz, Jorge, “La política exterior del cardenismo”, en León y GonZÁlez (coord.), pp. 370-435.

Martínez Legorreta, Omar, Actuación de México en la Liga de las Naciones: el caso España, México, Universidad Nacional Autónoma de México, 1962.

Matesanz, José Antonio, Las raíces del exilio. México ante la guerra civil española, 1936-1939, México, El Colegio de México, Universidad Nacional Autónoma de México, 1999.

McPherson, Alan y Yannick Wehrli, Beyond Geopolitics: New Histories of Latin America at the League of Nations, Albuquerque, University of New Mexico Press, 2015.

Meyer, Lorenzo, “Alberto J. Pani, embajador en España de entrada por salida”, en Sola Ayape (coord.), 2016, pp. 91-102.

Meyer, Lorenzo, La marca del nacionalismo, México, El Colegio de México, 2010.

Meyer, Lorenzo, México y los Estados Unidos en el conflicto petrolero (19171942), México, El Colegio de México, 1981.

Meyer, Lorenzo, Su Majestad británica contra la revolución mexicana (19001950), México, El Colegio de México, 1991. 
Miller, David Hunter, My Diary at the Conference of Paris with Documents, vol. xx: Conference Minutes \& Miscellaneous, s. l., Appeal Printing Company, s. a.

Ojeda Revah, Mario, "El frente diplomático: defensa mexicana de España ante la Sociedad de las Naciones", en Foro Internacional, 86 (2006), pp. 762791.

Ojeda Revah, Mario, “En busca de un lugar en el mundo, 1930-1960”, en OJEDA REVAH (coord.), pp. 197-263.

OJeda Revah, Mario, "La dimensión internacional de Lázaro Cárdenas”, en Gilly y OJeda Revah (coords.), pp. 31-55.

Ojeda Revah, Mario, México y la Guerra Civil española, Madrid, Turner, 2004.

OJeda Revah, Mario (coord.), La política internacional, 1808-2014, México, El Colegio de México, Fundación mapfre, Fondo de Cultura Económica, 2015.

Ortiz Rubio, Pascual, Memorias, Morelia, Universidad Michoacana de San Nicolás de Hidalgo, 1993.

Ortuño Martínez, Manuel, “Cárdenas, México y España”, en Leviatán: Revista de Hechos e Ideas, 61 (1995), pp. 133-149.

Palacios, Guillermo, América del Sur, México, Secretaría de Relaciones Exteriores, 2011.

Pani, Alberto J., Cuestiones diversas contenidas en 44 cartas al presidente Carranza, 1 carta al presidente De la Huerta, 1 artículo de 'El Universal' y 4 brindis, México, Imprenta Nacional, 1922.

Pani, Arturo J., Alberto J. Pani. Ensayo biográfico, México, Imprenta de Manuel Casas, 1961.

Perkins, Dexter, A History of the Monroe Doctrine, Boston, Little, Brown and Company, 1963.

Pi-Suñer, Antonia, Paolo Riguzzi y Lorena Ruano, Europa, México, Secretaría de Relaciones Exteriores, 2011. 
PorTes Gil, Emilio, Autobiografía de la revolución mexicana. Un tratado de interpretación histórica, México, Instituto Mexicano de Cultura, 1964.

Portes Gil, Emilio, Historia vívida de la revolución mexicana, México, Cultura y Ciencia Política, 1976.

Sáenz, Aarón, La política internacional de la revolución, México, Fondo de Cultura Económica, 1961.

SÁInz, Luis Ignacio, “México frente a la anexión”, en SÁINZ (coord.), pp. 67-84.

Sárnz, Luis Ignacio (coord.), México frente al Anschluss, México, Secretaría de Relaciones Exteriores, 1988.

SÁnchez Andrés, Agustín, "El espejo invertido: las relaciones hispanomexicanas durante la segunda república española (1931-1936)", en Sola AyAPE (coord.), 2016, pp. 105-135.

SÁnchez Andrés, Agustín, México en el siglo XX: del porfiriato a la globalización, Madrid, Arco Libros, 2010.

SÁNCHEz Andrés, Agustín, "México y la crisis del sistema de seguridad colectiva, 1931-1939", en Casa del Tiempo, 24 (oct. 2009), pp. 135-136.

Sánchez Andrés, Agustín y Pedro Pérez Herrero, Historia de las relaciones entre España y México, 1821-2014, Madrid, Marcial Pons, 2015.

Schiavon, Jorge A., Daniela Spenser y Mario Vázquez Olvera (eds.), En busca de una nación soberana: relaciones internacionales de México, siglos XIX $y X X$, México, Centro de Investigación y Docencia Económicas, Secretaría de Relaciones Exteriores, 2006.

Savarino Roggero, Franco, México e Italia:política y diplomacia en la época del fascismo, 1922-1942, México, Secretaría de Relaciones Exteriores, 2003.

Schuler, Friedrich E., Secret Wars and Secret Policies in the Americas, 18421929, Albuquerque, University of New Mexico Press, 2010.

Seara Vázquez, Modesto, Tratado general de la organización internacional, México, Fondo de Cultura Económica, 1985.

Serra Puche, Mari Carmen, José Francisco Mejía Flores y Carlos Sola Ayape (eds.), De la posrevolución mexicana al exilio republicano español, México, Fondo de Cultura Económica, Cátedra del Exilio, 2011. 
Serrano Migallón, Fernando, Isidro Fabela y la diplomacia mexicana, México, Porrúa, 1997.

Sola Ayape, Carlos (coord.), Los diplomáticos mexicanos y la Segunda República española (1931-1975), Madrid, Fondo de Cultura Económica, Cátedra del Exilio, Fundación Pablo Iglesias, 2016.

Spenser, Daniela, "Forjando una nación posrevolucionaria: México, la Unión Soviética y Estados Unidos", en Schiavon, Spenser y Vázquez Olvera (eds.), 2006.

Streeter, Michael, Central America and the Treaty of Versailles, Londres, Haus Publishing, 2010.

TARACENA, Alfonso, La verdadera revolución mexicana: quinta etapa (19161918), México, Jus, 1979.

Tello, Manuel, "Algunos aspectos de la participación de México en la Sociedad de las Naciones", en Foro Internacional, vi: 2-3 (oct.-dic. 1965), pp. 358-383.

Tirado SÁnchez, Aránzazu, "La política exterior del México cardenista hacia la segunda república española. El caso del exilio republicano en México: ¿cooperación ideológica o interés pragmático?”, tesis de doctorado en relaciones internacionales e integración europea, Barcelona, Universidad de Barcelona, 2007.

Trow, Clifford W., "Woodrow Wilson and the Mexican Interventionist Movement of 1919", en The Journal of American History, 58: 1 (1971), pp. 46-72.

Walters, Francis Paul, Historia de la Sociedad de Naciones, Madrid, Tecnos, 1971.

WeHrLI, Yannick, “'Créer et maintenir l'intérêt': la liaison entre le Secrétariat de la Société des Nations et l'Amérique latine (1919-1929)", tesis de licenciatura en historia, Ginebra, Université de Genève, 2003.

WeHrLI, Yannick, "États latino-américains, organismes multilatéraux et défense de la souveraineté. Entre Société des Nations et espace continental panaméricain (1919-1939)", tesis de doctorado, Ginebra, Université de Genève, 2016.

Zea Prado, Irene, "México en la Sociedad de Naciones", en Relaciones Internacionales, 68 (oct.-dic. 1995), pp. 115-122. 